\title{
Construction on Course System for Undergraduate Specialty of Social Sports Guidance and Management
}

\author{
Guoquan Zhang \\ Department of Physical Education, Bohai University, Jinzhou, 121013, China \\ 673722120@qq.com
}

Keywords: social sports guidance and management; undergraduate specialty; training requirement; course system; core course

\begin{abstract}
Course system refers to different courses in the same specialty are arranged according to the order of the categories, determines students how to acquire the knowledge structure through the study. This paper studied the existing problems of the course system construction for undergraduate specialty of social sports guidance and management. Firstly, research the training requirements, build professional ability structure training model of social sports guidance and management; then, study course system, build undergraduate specialty course architecture of social sports guidance and management; finally, the core course description, including sports management, sports physiology, introduction to social sports, theory and methods of physical exercise, sports economics, and so on. The research results of this paper plays an important role for improving the quality of training and meeting the needs of the society.
\end{abstract}

\section{Introduction}

Social sports professional students mainly study the basic theory and basic knowledge of the social sports, get the basic training from social sports work, to grasp the basic ability of the mass sports activities organization management, consulting guidance, management development and teaching research and so on. Sport is sport in people's life, it is a kind of people's way of life, along with the increase of public health awareness and demand, as well as the development of sports industry, and mainly to cultivate the PE teachers, its physical education major has been unable to meet the needs of the social sports diverse talents [1]. Therefore, in order to foster a fitness guide and sports industry management personnel consisting mainly of social sports specialty emerged. Social sports guidance and management program aims at training students with sports theory, theory of education, humanities and social sciences and the basics of economic management, with the scientific concept of leisure sports and market development awareness, able to grasp the rules of leisure sports activities and insight into sports leisure market changes, in leisure sports activities, effectively engaged in the promotion, guidance, management and planning, effectively carry out product planning, design and development, and to organize various leisure sports talent.

Course system refers to different courses in the same specialty are arranged according to the order of the categories, is the sum of the content and process of teaching, the order of course categories arrangement determines the students will gain what kind of knowledge structure by learning. Course system is the guiding ideology of educational activity, is the specific and support of training goal, it provides for the planning program of the implementation of the training objectives. Course system is mainly composed by a specific course concept, course objectives, course content, course structure and course activities, which play a dominate role in course concept [2]. According to the existing problems of social sports guidance and management undergraduate specialty course system construction, and professional ability structure training model of social sports guidance and management, to built on the scientific courses sports, for foster social sports guidance and management professional talents service.

\section{Training Requirement}

earning basic theoretical knowledge of social sports guidance and management, master the basic 
skills of social sports guidance and management, basic theory and basic knowledge, receive basic training about sports specialty skill and sociology and histology, management and other aspects, with the masses sports activities organization and management, technical guidance, business development, propaganda and reporting capabilities. The graduates should acquire the following knowledge and abilities: grasp the basic principles of Marxism, Mao Zedong thought, Deng Xiaoping theory, the important thought of "three represents" and the scientific concept of development, have a solid foundation of natural science knowledge and the specialty required technology base and professional knowledge; to understand the social sports guidance and management and the dynamics and trends of industrial development; grasp the basic knowledge of sports industry management, fitness instruction, health rehabilitation guidance and other aspects, basic techniques and basic skills; Having the ability about independent acquire the professional knowledge, update knowledge and apply knowledge, having the ability to independently analyze and solve practical problems in the professional field, to carry out scientific research and sports science and technology development; basic master a foreign language, can read professional foreign language books, general session; have the basic skills to use computers; with more strong adaptability, affordability and interpersonal skills, physical health, mental state is good. The above training requirements summarized as the ability to structure training model, as shown in table 1.

Table 1. Ability structure training model of Social sports instruction and management specialty

\begin{tabular}{c|l}
\hline Structure type & \multicolumn{1}{c}{ Constituent elements } \\
\hline Basic structure & (1) Master the basic knowledge of social sports theory \\
(2) Master basic theoretical knowledge of professional sport \\
(3) Has the basic theoretical knowledge of training guidance \\
(4) Has the management knowledge of sports industry \\
(1) Master the technical capability of sports projects \\
(2) Proficiency in two professional sports technology \\
(3) Master the means of mass fitness \\
(4) Master the work of the sports competition arrangement and organization \\
(5) The ability to develop and manage sports industry \\
(6) The ability of fitness training, leisure counseling and guidance \\
(7) Physical education, sports training theory and skills \\
(8) Master the ability of sports training skills \\
(9) Master the basic skills and knowledge of outdoor sports \\
(1) Have good ideological and moral qualities \\
(2) Have a healthy psychological \\
(3) Have the certain computer application ability \\
(4) Scientific employment view and good professional quality \\
(5) Have a certain level of English application
\end{tabular}

\section{Course System}

Social sports guidance and management in the past practice of running school has achieved fruitful results, but many failings exist in the curriculum sports construction, mainly in following areas [3]:

(1) The course structural imbalance. The course structure is the organization form which is in accordance with the rules between the various types, the various elements and the various components of the internal course. Course structure mainly solves the coordination problems between the various parts of the course content Professional courses and basic courses and elective courses and required courses, the proportion of some imbalance, the relative lack of professional basic courses classes, attention degree is not enough, is not conducive to the students to master the systematic and solid theoretical foundation of professional knowledge and skills.

(2) The course setting is not reasonable. Course setting is the establishment and arrangement of the various types of schools selected courses, including the open course, the order of the course and the arrangement of the contents. Some courses have no direct contact with the professional training 
direction, which makes some students have vague position in the direction of professional training, some of the practical application of the theoretical courses is not strong, should be effective trade-offs;

(3) Professional practice teaching system is weak. Social sports guidance and management specialty is a practical and applied strong professional, to students' practical skills have higher requirement, such as management skills, marketing skills, fitness guide skills, interpersonal skills, good image and temperament cultivation and other practical ability. On the one hand, the lack of a relatively stable practice base outside school professional practice, seriously affecting the quality of teaching practice. On the other hand, the organization form and content of the specialized course practice is single, the practice teaching is more difficult to operate.

For the current existing problems of social sports guidance and management course system construction, should take the social demand as the guidance, based on the practice of running schools, updated ideas, reasonable positioning, strengthen management. Making course system construction should follow the following principles: optimize course structure and course setting to meet the needs of society; actively establish school-enterprise cooperation practice base, and enhance the professional educational strength; to improve school conditions, strengthen teaching management, to provide protection for the optimization of course system [4-6]. This paper constructs social sports guidance and management course system is shown in Fig. 1.

\section{Core Course}

The core courses of the social sports guidance and management specialty briefly described as follows:

(1) Sports management. Use management theory and methods, to research the coordination of sports organizations in order to achieve a predetermined sports targets discipline. Since the management system mainly consists of three aspects: the management, the management objects and the management means, so its research objects include managers and as managers financial, material, time, information, and manage forms and methods. Contents include: the basic principle of sports management; the development history of sport management; sports management system; functions of sport management; sports management processes and methods; the management form and method of all kinds of sports. In practical applications, often used in the field classification method, namely school sports management, competitive sports management, and the masses sports management, and so on. Research methods include observation, investigation, experiment, comparison, analysis and case studies.

(2) Exercise physiology. So that students master the basic theory and basic knowledge of exercise physiology, and through the experimental class and social practice, to develop students' ability to find problems, analyze problems and solve problems. To enable students to apply basic theory and method of the exercise physiology, guide and evaluate physical education, sports training, and physical exercise, and basic methods of assessing human body functions primarily preliminary master. Through classroom instruction and experiments to understand the phenomenon of the normal physiological activity, the laws and regulatory mechanisms, to master the basic theory and basic knowledge; grasp the impact of the various systems and organ function of the body and the basic mechanisms of physical activity; master the physiology principles of physical exercise and extracurricular sports training and the physiology evaluation of exercise effect, guiding physical education, sports training practice and fitness activity.

(3) Introduction to social sports. From different aspects, elaborated the knowledge of social sports, competitive sports and market rules other aspects, for students to understand the cultural values of sport, social connotation, market value, market operations and the improvement of appreciation level of sports beauty and sports photography capability has a good ability guidance. Teaching tasks are as follows: the explicit task of the purpose of social sports, systematically master the basic principles, rules and methods, to understand the full development of sports psychology dynamics, characteristics and trends; clearly know the responsibilities of coaches and coaches should have the knowledge structure and the ability structure, solid establish professional thinking, 
loyal to the party's sports career, to be a qualified coach; the actual use of the operating capacity of the various methods of social sports organization, and in accordance with the basic requirements of the plan formulation, to lay a foundation for the future in the professional work.
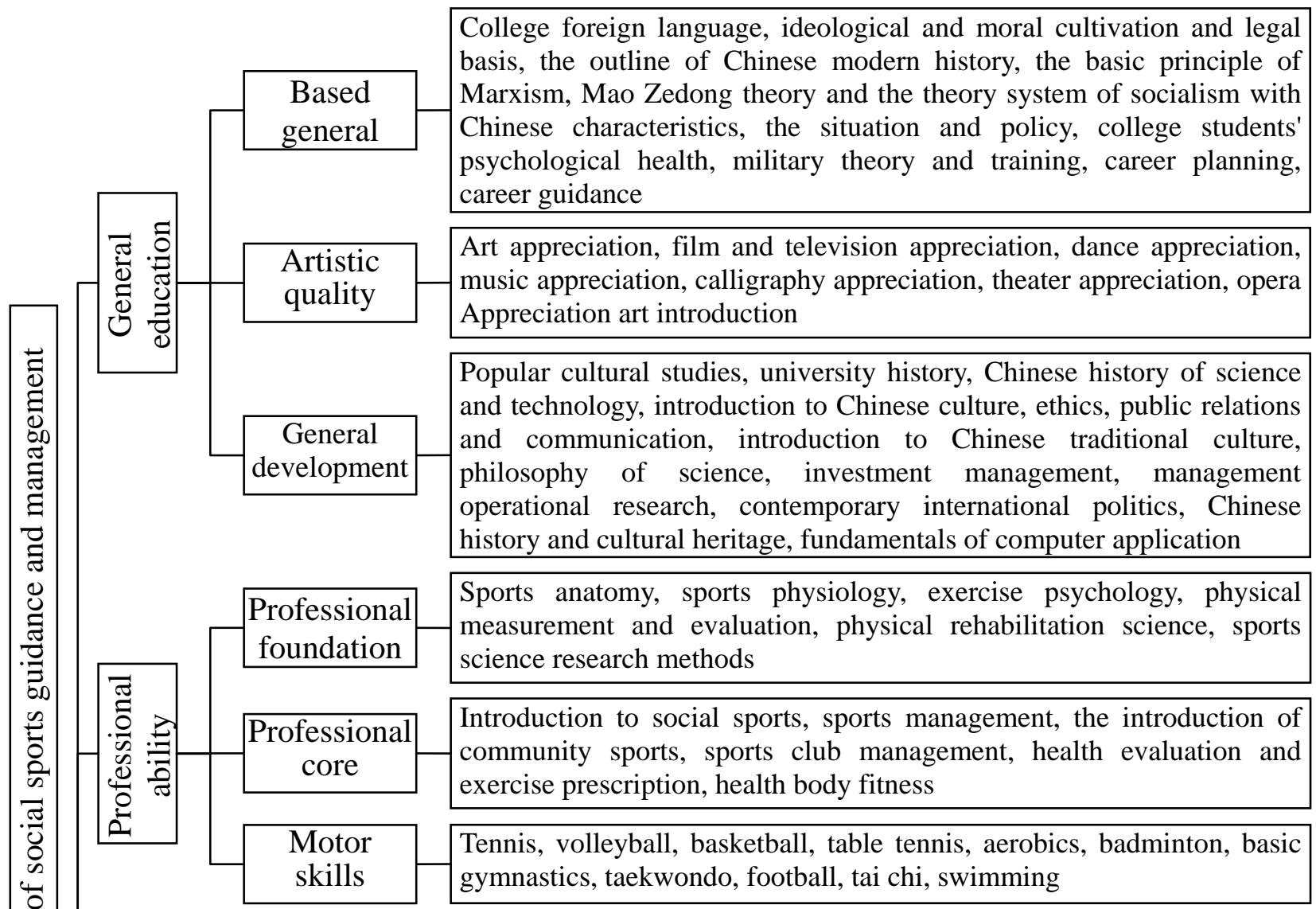

Sports anatomy, sports physiology, exercise psychology, physical measurement and evaluation, physical rehabilitation science, sports science research methods

Introduction to social sports, sports management, the introduction of community sports, sports club management, health evaluation and exercise prescription, health body fitness

Tennis, volleyball, basketball, table tennis, aerobics, badminton, basic gymnastics, taekwondo, football, tai chi, swimming

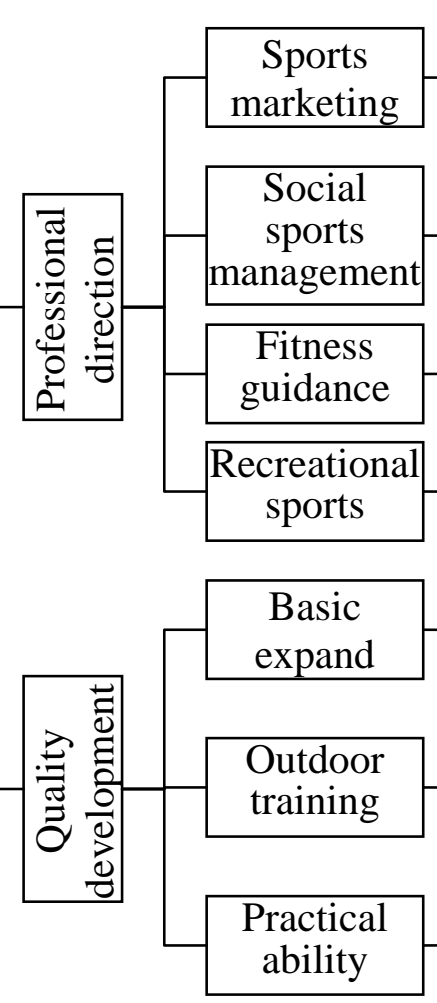

Introduction to sports marketing, sports marketing research and analysis, sports sponsorship, sports industry management, sports marketing, sports economy introduction

Social sports management, introduction to social sports organization and management, sociology, social sports instructor introduction, sports event planning and management

Theory and methods fitness, sports nutrition, fitness equipment, first aid and prevention of sports injuries, fashion aerobic fitness dance

Sports and leisure theory, billiards, lawn bowls, sports or leisure theory and practice, bocce, yoga, hip-hop, skating

Sports tourism, sports agent, sports marketing case, sports prescription, physical training, yoga, communication theory, Mandarin, sports nutrition

Directional cross-country, expand training, outdoor survival, introduction of outdoor instructor, basic mountaineering skills, emergency treatment of emergency incidents, mountain outdoor sports

Innovation ability, knowing and evaluation, outside school practice of ideological and political theory, graduation practice, graduation thesis, professional practice, and professional major capacity evaluation

Fig. 1. Course system on undergraduate specialty of social sports guidance and management

(4) The theory and method of fitness movement. Through teaching practice, students understand the method and evaluation of fitness training, the structure and composition of the 
fitness activities, and mainly introduce the fitness method of the health problems. The purpose is to make students master the methods and evaluation of building a comprehensive and systematic fitness training, master fitness activities structures, methods and means; and to understand the specific methods and ways of promoting and improving the health level. To train the ability of sports specialty in a comprehensive, systematic teaching fitness approach. Through teaching practice, the students can systematically master the basic knowledge, basic techniques and basic skills of fitness, initially to achieve "speaks, will do, will guide".

(5) Sports economics. It is an integral part of modern economics, which is the product of the combination of physical education and economics. A comprehensive and systematic study of the relationship between sports and the economy; and to study the sports how affected by economic constraints, but also how to promote economic development; explore the rules and characteristics of the sports industry production, exchange, distribution, and consumption, as well as the nature, characteristics and development law discipline of the economic phenomenon, the process of economic activity in the field of sport.

\section{Conclusion}

The course system will be the permutations and combination of the various constituent elements of the course, so that all the course elements in the dynamic process unified point to the system that the course system goal to achieve, it is to achieve the carrier of the goal, is the key to ensure and improve the quality of education. With the increasing of the social economic development, the rising of people's living standard, the increasing of leisure time, people pay more and more attention to their own physical and mental health, so as to promote the vigorous development of the national fitness activities. The demand of the society to the multi-level and diversified social sports talents is increasing rapidly, while the overall quality of social sports talent also made newer and higher requirements. This paper constructs the social sports guidance and management professional course system, for improving the quality of training, to meet the social needs, has an important role.

\section{References}

[1] HAO Xiao-gang, GAO Xue-mei, "A comparative study on the orientation of talent cultivation and the demand of the society of guidance and management of social sports specialty," Microcomputer \& Its Applications, vol. 36, no. 6, pp. 11-13, 2014.

[2] LUO Xiguang, LIN Minghong, "Research on the Curriculum Guidance and Management of Social Sports Specialty in China: Taking Guangdong Ocean University as An Example," Hubei Sports Science, vol. 32, no. 10, pp. 931-933, 2010.

[3] MING Peng-fang, "Research on the optimization of the curriculum system of the social sports guidance and management: Case study of Hubei science and technology institute of physical education," Journal of Hubei University for Nationalities(Philosophy and Social Sciences), vol. 33, no. 2, pp. 185-188, 2015.

[4] LIANG Han-ping, "Study of Curricular Design for Social Sport Guidance and Management Based on Students' Needs Analysis," Journal of Liupanshui Normal University, vol. 25, no. 6, pp. 32-37, 2013.

[5] LIN Yong, YU Yangfei, ZHAO Jigang, "The present situation and optimization strategy of social sports instruction and Management Specialty Curriculum: The research object is to study the social sports guidance and management of Tonghua Normal University," Journal of Tonghua Normal University, vol. 35, no. 4, pp. 98-100, 2014.

[6] Ge Yanrong, Jiang Fang, Research on Undergraduate Curriculum for the Major of Social Sports Guidance and Management," Journal of Environmental Management College of China, vol. 24, no. 1, pp. 69-73, 2014. 